\title{
Evaluation of the Treatment Complexity with Single Complete Removable Denture: A Cross-sectional Study in Tunisia
}

\author{
Sana Bekri ${ }^{1}$, Amel Labidi $^{2}$, Yosra Mabrouk ${ }^{3}$, Hiba Triki $^{4}$, Lamia Mansour ${ }^{5}$, Kamel B Salem ${ }^{6}$
}

\begin{abstract}
Aim: The aim of this study is to determine the complaints of patients wearing single complete removable dentures (SCRDs), to evaluate their satisfaction degree, and to identify the main construction faults committed.

Materials and methods: One hundred patients with SCRDs were included. A questionnaire was prepared to investigate the patients' complaints and satisfaction. This questionnaire was supplemented by a professional examination of dentures.

Results: Loss of retention and chewing difficulties were the most common complaints of the patients. Examination of the complete dentures by a professional in removable prosthodontics has shown prosthetic instability, lack of retention, and poor adaptation of the prosthetic bases in $49 \%, 42 \%$, and $38 \%$ of the cases, respectively. Occlusal errors related to balanced occlusion, occlusal plane orientation, and occlusal vertical dimension were found successively in $41 \%, 37 \%$, and $27 \%$ of the examined dentures, respectively. Sixty-three percent of the patients were overall dissatisfied with their dentures. This dissatisfaction was correlated to the quality of the denture $\left(p<10^{-3}\right)$.

Conclusion: The complaints expressed by the patients with their dentures are mostly justified. The design of a single removable denture does not seem to be mastered by many practitioners.
\end{abstract}

Keywords: Complaints, Patient satisfaction, Quality assessment, Single complete removable denture.

The Journal of Contemporary Dental Practice (2019): 10.5005/jp-journals-10024-2621

\section{INTRODUCTION}

In 1923, Gillet wrote, "The next decade will witness the end of removable and fixed prostheses..."1 A century later, removable dentures still exist and tooth loss remains uncontrolled.

To compensate edentulism, the implant-supported prosthesis is an attractive therapeutics. However, it is not within the reach of all patients either due to financial limits or medical reasons.

Thus, conventional complete removable dentures still occupy an important place in gerodontology with an increasing demand, especially with the prolongation of life expectancy. It is worth noting that the realization of this type of restoration is considered by most dentists as a complex prosthetic act. This complexity is more important when total edentulism concerns only a single arch. ${ }^{2}$

The number of studies focusing on the specific difficulties in relation to SCRD is relatively scarce despite the importance of the subject. The objective of this study was to determine the complaints and the satisfaction degree of patients with SCRD; to highlight the main possible construction faults, to better manage this type of restoration; and, therefore, to boost the quality of care provided to these patients.

\section{Patients and Method}

A cross-sectional survey was conducted for 7 months, from 1 May to 30 November 2017, on 100 patients at the Department of Removable Prosthodontics at the Faculty of Dental Medicine of Monastir, Tunisia.

\section{Inclusion Criteria}

Patients with SCRD who consulted following complaints with regard to their complete denture were included in the study. These patients were either completely toothed or partially toothless in the opposed arch. Informed consent was obtained from each subject participating in this study. \begin{tabular}{l}
\hline $1-5$ Department of Removable Prosthodontics, Faculty of Dental \\
Medicine, University of Monastir, Tunisia \\
${ }^{6}$ Department of Community Medicine, Faculty of Medicine, University \\
of Monastir, Tunisia \\
Corresponding Author: Sana Bekri, Department of Removable \\
Prosthodontics, Faculty of Dental Medicine of Monastir, Tunisia, Phone:
\end{tabular} Prosthodontics, Faculty of Dental Medicine of Monastir,
+216 21756809, e-mail: sanabekri2015@gmail.com

How to cite this article: Bekri S, Labidi A, et al. Evaluation of the Treatment Complexity with Single Complete Removable Denture: A Cross-sectional Study in Tunisia. J Contemp Dent Pract 2019;20(8): 957-962.

Source of support: Nil

Conflict of interest: None

\section{Exclusion Criteria}

Patients presenting the following criteria were excluded:

- SCRD less than 6 months old (6 months is considered as the period of denture integration)

- A mental deficit

- Using prosthetic adhesives

- Having Sjogren's syndrome

- Wearing immediate or implant-supported SCRD

- Presenting with fractured denture

- Denture age less than 1 month, this period considered necessary to adapt to the new dentures

Data collection was performed by one examiner (specialist of removable prosthodontics) using a pretested questionnaire including 17 questions (Fig. 1) and investigated the following main aspects: the patient's sociodemographic characteristics, the consultation motive, and the level of satisfaction with the removable

(c) The Author(s). 2019 Open Access This article is distributed under the terms of the Creative Commons Attribution 4.0 International License (https://creativecommons. org/licenses/by-nc/4.0/), which permits unrestricted use, distribution, and non-commercial reproduction in any medium, provided you give appropriate credit to the original author(s) and the source, provide a link to the Creative Commons license, and indicate if changes were made. The Creative Commons Public Domain Dedication waiver (http://creativecommons.org/publicdomain/zero/1.0/) applies to the data made available in this article, unless otherwise stated. 


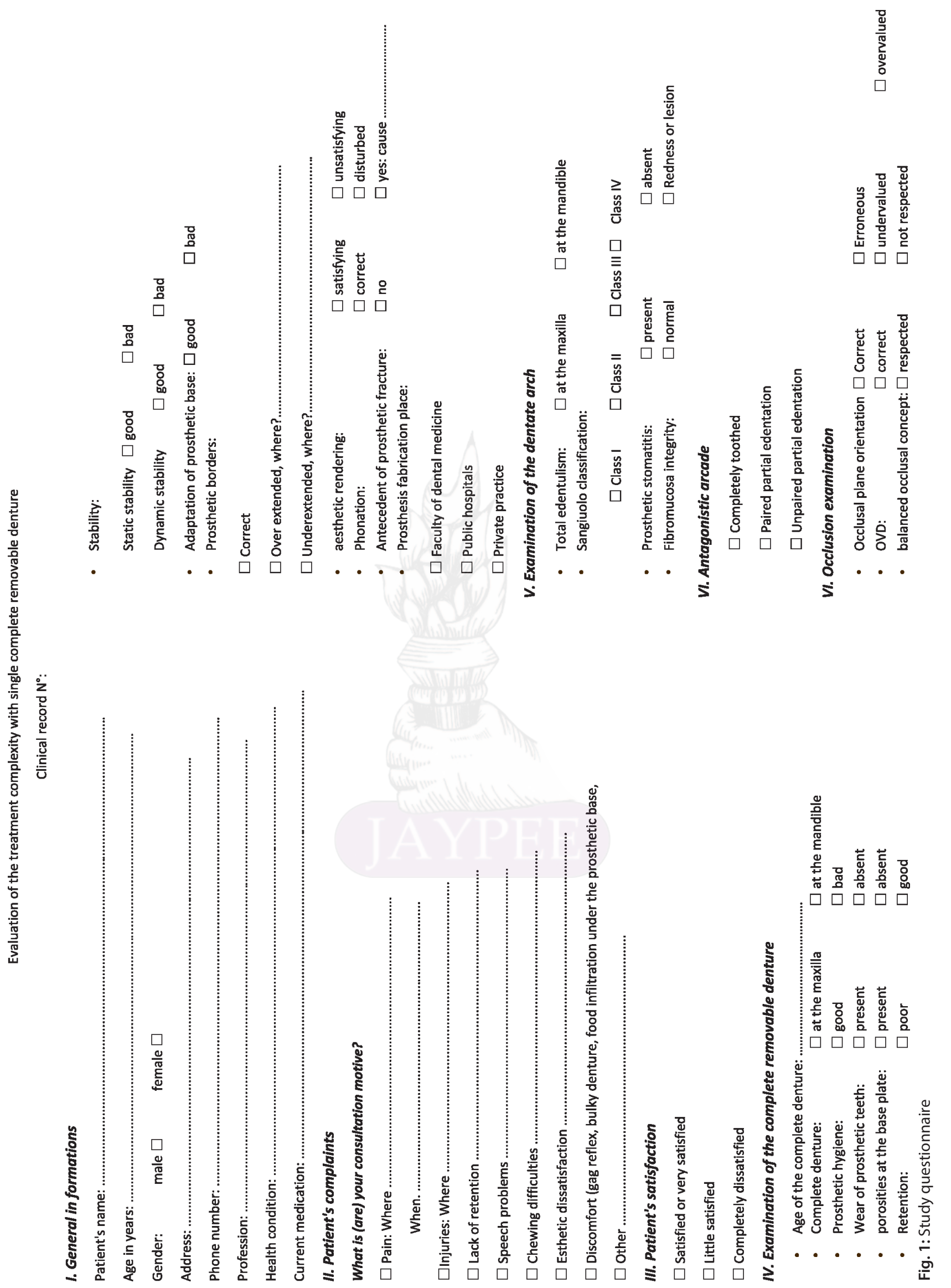


complete denture. This questionnaire was supplemented by a clinical examination of the edentulous arch, the complete denture, and its antagonist (in case it exists) and occlusion done by the same examiner.

Statistical analysis of the data was done using the SPSS version 17.0. The Pearson Chi-square and the Fisher tests were then used to study the correlation between the qualitative variables with a significant $p$ value $<0.05$.

\section{Operational Definitions}

\section{Quality of Complete Dentures}

According to the Ejvind-Jorgensen and Mojon, ${ }^{3}$ retention, stability, occlusion, and adaptation of the denture based on the underlying tissues were the important criteria to be evaluated. These criteria allow the classification of the denture quality as follows:

Group I: satisfactory for the four criteria, group II: satisfactory for 2-3 criteria, and group III: satisfactory for 0-1 criteria.

For the statistical analysis, we considered that the dentures belonging to group I or II are acceptable, whereas those belonging to group III are unacceptable and need to be replaced.

\section{Overall Satisfaction}

For the statistical analysis, the patients completely dissatisfied or little satisfied were grouped in the "overall dissatisfied" group, and the patients satisfied and very satisfied were grouped in the "overall satisfied" group.

\section{Results}

Our sample involved 100 patients, 31 females and 69 males (sex ratio of 2.22). The mean age was $62.4 \pm 11$.74 years ranging between 35 years and 90 years. Forty-six percent of the patients were in good general health, $30 \%$ diabetic, $2 \%$ having osteoporosis, and $22 \%$ presenting other diseases. The SCRDs were realized at the Faculty of Dental Medicine (43\%), in public hospitals (36\%), or in private practice (21\%). Among these patients, $74 \%$ had complete edentulism at the maxilla vs $26 \%$ at the mandible.

According to the Sangiuolo classification, more than half of these edentulism were classes I (58\%) and II (23\%). Classes III and IV were found in $12 \%$ and $7 \%$ of the patients, respectively.

Each patient reported on an average of 2.55 complaints in relation to the complete denture; patients were also investigated concerning their satisfaction with SCRD. Their responses are presented in Table 1.

The results of the professional examination of SCRD are shown in Table 2.

During the patients' investigation, 29 patients reported also a history of complete dental fractures.
Using the classification of Jorgensen Ejvind and Mojon, ${ }^{3}$ we found that $33 \%$ of SCRD belong to group I, $43 \%$ to group II, and $24 \%$ to group III.

The statistical analysis showed a very significant association between lack of retention and prosthetic instability $\left(p<10^{-3}\right)$. Similarly, we noted that retention was generally good for class I of Sangiuolo followed by class II and that the general health status could affect the prosthetic retention $(p<0.05)$ (Table 3$)$.

Erroneous occlusal planes were associated with prosthetic instability, phonetic disorders, and chewing difficulties (Table 4). According to our study, the patients' satisfaction with their SCRD was closely dependent on the denture quality $\left(p<10^{-3}\right)$ (Table 5 ). About $83.3 \%$ of poor quality dentures were fabricated outside the faculty; the correlation in Table 6 between the fabrication place and the denture quality was significant $(p=0.028)$.

\section{Discussion}

It is common to see patients with SCRD complaining of various problems. This could constitute a public health problem because of the additional expenses required if we are obliged to remake the denture.

Our sample, characterized by male predominance, was not representative of the Tunisian population whose sex ratio is $0.99 .^{4}$ This could be explained by the unavailability of women due to their household concerns, which limits their movements, and by the fact that they are generally more motivated with regard to their oral hygiene. The mean age of our patients was $62.4 \pm 11.74$, which was close to that of Bilhan et al. ${ }^{5}$ who reported means varying between 64 and 65 years.

Complete maxillary edentulism was more frequently encountered within the sample; this is because mandibular teeth often benefit from better implant condition and are, therefore, lost at a later age.

In addition, practitioners are often aware of the difficulty of ensuring balance for a mandibular complete denture given the reduced supporting area. They are, therefore, more conservative at the mandible.

All the patients investigated claimed an average of 2.55 complaints, this seems logical. In fact

- In the case of unstable, non-retentive, or pain provocative dentures, patients could complain of difficulties in chewing and speech.

- In the case of bulky dentures, esthetic, reflexogenic, or speech problems could be claimed.

Loss of retention preceded all the other complaints mentioned by patients, which corroborates the results of other authors. ${ }^{5,6}$ However, it is important to note that this complaint does not necessarily correspond to the absence of retention. In fact, patients

Table 1: Complaints and satisfaction degree of patients with SCRD

\begin{tabular}{|c|c|c|c|c|c|c|c|c|}
\hline & $\begin{array}{c}\text { Lack of } \\
\text { retention (n) }\end{array}$ & $\begin{array}{c}\text { Chewing } \\
\text { difficulties (n) }\end{array}$ & Pain (n) & Injuries (n) & $\begin{array}{l}\text { Speech } \\
\text { problems }(n)\end{array}$ & $\begin{array}{c}\text { Esthetic in } \\
\text { satisfaction (n) }\end{array}$ & Discomfort (n) & $\begin{array}{c}\text { Loss of } \\
\text { artificial teeth }\end{array}$ \\
\hline \multirow{2}{*}{$\begin{array}{l}\text { Patients' } \\
\text { complaints }\end{array}$} & 75 & 57 & 32 & 27 & 25 & 19 & 12 & 8 \\
\hline & & \multicolumn{3}{|c|}{ Satisfied or very satisfied (\%) } & \multicolumn{2}{|c|}{ Little satisfied (\%) } & \multicolumn{2}{|c|}{ Completely dissatisfied (\%) } \\
\hline \multicolumn{2}{|l|}{ Patients'satisfaction } & \multicolumn{3}{|c|}{37} & \multicolumn{2}{|l|}{34} & \multicolumn{2}{|l|}{29} \\
\hline
\end{tabular}


Table 2: Professional examination of SCRD

\begin{tabular}{ll}
\hline Dentist observation & $\begin{array}{l}\text { Percentage of } \\
\text { SCRD (\%) }\end{array}$ \\
\hline Instability (static and/or dynamic) & 49 \\
Poor retention & 42 \\
Bad adaptation of denture base & 38 \\
Over or under-extended borders & 36 \\
Prosthetic teeth wear & 17 \\
Poor aesthetic & 18 \\
Phonation disturbance & 23 \\
Errors in balanced occlusal concept & 41 \\
Erroneous occlusal plane orientation & 37 \\
Erroneous occlusal vertical dimension (OVD) & 27 \\
\hline
\end{tabular}

Pain constituted the third consultation motive in our sample, unlike some other studies ${ }^{9,10}$ where it was the most common complaint. In all cases, the information given by the patients was not enough. The search for tangible oral signs explaining pain such as wounds or compressions was mandatory.

Some patients also reported speech disorder. The difficulty of phonemes emission is common on the day of the prosthesis insertion and it disappears a few weeks later. When it persists, an erroneous ODV, errors in teeth mounting, prosthetic instability, lack of retention, or an extra-thickness of the base plate could be implicated. ${ }^{11,12}$

At the beginning of our study, we thought that esthetic complaints would be the most important, as the opposing arch presents residual teeth that are generally difficult to harmonize with complete dentures. Yet, it was surprising that only one-fifth of the patients had esthetic problems.

Table 3: Factors influencing the retention of SRCD

\begin{tabular}{|c|c|c|c|c|c|c|c|c|c|}
\hline \multirow[b]{2}{*}{ Retentio } & & \multicolumn{2}{|c|}{ Stability } & \multicolumn{2}{|c|}{ General health status } & \multicolumn{4}{|c|}{ Class of Sangiuolo } \\
\hline & & Stable & Unstable & Good & Altered & Class I & Class II & Class III & Class IV \\
\hline \multirow[t]{2}{*}{ Poor } & $n$ & 18.0 & 40.0 & 22.0 & 36.0 & 27.0 & 13.0 & 11.0 & 7.0 \\
\hline & (\%) & 31.0 & 69.4 & 38.0 & 62.0 & 46.6 & 22.4 & 19.0 & 12.1 \\
\hline \multirow[t]{2}{*}{ Good } & $n$ & 33.0 & 9.0 & 24.0 & 18.0 & 31.0 & 10.0 & 1.0 & 0.0 \\
\hline & $(\%)$ & 78.6 & 21.4 & 57.2 & 42.8 & 73.8 & 23.8 & 2.4 & 0.0 \\
\hline$p$ & & \multicolumn{2}{|c|}{$<0.001^{*}$} & \multicolumn{2}{|c|}{$<0.05^{*}$} & \multicolumn{4}{|c|}{$<0.05^{*}$} \\
\hline
\end{tabular}

Table 4: Relation between occlusal plane and stability, chewing, phonation

\begin{tabular}{|c|c|c|c|c|c|c|c|c|c|c|c|c|}
\hline \multirow[b]{3}{*}{ Occlusal plane orientation } & \multicolumn{4}{|c|}{ Stability } & \multicolumn{4}{|c|}{ Chewing } & \multicolumn{4}{|c|}{ Phonation } \\
\hline & \multicolumn{2}{|c|}{ Stable } & \multicolumn{2}{|c|}{ Unstable } & \multicolumn{2}{|c|}{ Normal } & \multicolumn{2}{|c|}{ Difficult } & \multicolumn{2}{|c|}{ Normal } & \multicolumn{2}{|c|}{ Disturbed } \\
\hline & $n$ & (\%) & $n$ & (\%) & $n$ & (\%) & $n$ & (\%) & $n$ & (\%) & $n$ & (\%) \\
\hline Correct & 48 & 76.2 & 15 & 23.8 & 42 & 66.7 & 21 & 33.3 & 59 & 93.7 & 04 & 06.3 \\
\hline \multirow[t]{2}{*}{ Erroneous } & 03 & 8.1 & 34 & 91.9 & 01 & 2.7 & 36 & 97.3 & 18 & 48.6 & 19 & 51.4 \\
\hline & \multicolumn{4}{|c|}{$p<10^{-3 *}$} & \multicolumn{4}{|c|}{$p<10^{-3 *}$} & \multicolumn{4}{|c|}{$p<10^{-3 *}$} \\
\hline Odds ratio & \multicolumn{4}{|c|}{$3.86(2.45-6.06)$} & \multicolumn{4}{|c|}{$2.919(2.05-4.15)$} & \multicolumn{4}{|c|}{$8.08(2.98-21.96)$} \\
\hline
\end{tabular}

Table 5: Patients' satisfaction in relation to the dentures quality

\begin{tabular}{|c|c|c|c|c|c|c|c|}
\hline \multirow[b]{3}{*}{ Overall satisfaction } & \multicolumn{6}{|c|}{ SCRD qualities } & \multirow[b]{3}{*}{$p$} \\
\hline & \multicolumn{2}{|c|}{ Group I } & \multicolumn{2}{|c|}{ Group II } & \multicolumn{2}{|c|}{ Group III } & \\
\hline & $n$ & (\%) & $n$ & (\%) & $n$ & (\%) & \\
\hline Overall satisfied & 21 & 63.6 & 14 & 32.6 & 2 & 8.3 & $<0.001$ \\
\hline Overall dissatisfied & 12 & 36.4 & 29 & 67.4 & 22 & 91.7 & \\
\hline
\end{tabular}

Table 6: Correlation between fabrication place and SCRD quality

\begin{tabular}{|c|c|c|c|c|c|}
\hline \multirow[b]{3}{*}{ Place of realization } & \multicolumn{4}{|c|}{ SCRD quality } & \multirow[b]{3}{*}{$p$} \\
\hline & \multicolumn{2}{|c|}{ Acceptable } & \multicolumn{2}{|c|}{ Unacceptable } & \\
\hline & $n$ & (\%) & $n$ & (\%) & \\
\hline Dental faculty & 39 & 51.32 & 4 & 16.67 & 0.028 \\
\hline Other & 37 & 48.68 & 20 & 83.30 & \\
\hline
\end{tabular}

do not differentiate among static instability, dynamic instability, and lack of retention.

Complaints with regard to chewing problems occupied the second position. This complaint depends on several parameters such as the patient's subjectivity, prosthetic instability, tissue lesions causing a relative impossibility to masticate, and the psychological decrease of this function in elderly subjects. ${ }^{7,8}$
The examination of SCRD by a professional in removable prosthodontics showed a high frequency of prosthetic instability (49\%) and loss or lack of retention (42\%).

According to our study, there is a statistically significant association between SCRD instability and loss of retention $\left(p<10^{-3}\right)$. This instability is seen in the static state in association with a poor adaptation of the bases to their supporting areas, 
prosthetic over or under extended borders, or an inappropriate peripheral seal. It could also be seen in the dynamic state following a prematurity or interference.

Apart from these construction faults, some anatomo-clinical factors such as the Sangiuolo class and the general health status also affected the retention of complete dentures $\left(p<10^{-5}\right)$.

In fact, alveolar resorption in its final stages (classes III and IV of Sangiuolo) was at the origin of poor retention. This requires a quantitative and qualitative assessment of the supporting area as well as a mastery of this phenomenon by an atraumatic avulsion maneuver followed by the use of an immediate prosthesis stimulating osteogenesis.

Although no statistical link was established between each of the pathologies present in our sample and the retentive quality of SCRD, but poor retention (62\%), as shown in Table 1, was generally associated with an altered health condition. This was expected for the pathologies known for their effects on bone or on the salivary function.

Prosthetic poor adaptation on bearing areas concerned an important part of SCRD. This could be due to bad impressions, but especially because of imbalance between opposing teeth proprioception and mucosal exteroception in the totally edentulous arch. This imbalance reinforces the role of periodontal proprioceptors at the expense of mucosal exteroceptors. This leads to an overload of the osteomucous supporting tissues and secondarily to bone resorption.

Consequently, it results in a poor adaptation of SCRD on their supporting tissues which is responsible for prosthetic injuries, lack of retention, and prosthetic instability.

Mbodj et al. ${ }^{13}$ contradicted this theory and reported that SCRDs were less rebased than bimaxillary complete removable dentures and caused a fewer mucosal lesions. Nevertheless, we can attribute the results of Mbodj's study to the regularities of prosthetic checkups and occlusal maintenance. On the contrary, we found that bilateral occlusal balance concept was not respected for $41 \%$ of SCRD. This was the case when prosthetic teeth mounting was performed in normal occlusion with anterior contacts and guidance, or when practitioners adapted SCRD to existing disturbed occlusion curves. The instability caused by the neglect of the balanced occlusion may explain in a great part the fractures of the prosthetic bases. ${ }^{14}$

Naik ${ }^{15}$ reported that the main cause was rather accidental fractures, followed by poor adaptation and then bad occlusion. For Khasawneh and Arab, ${ }^{16}$ maladjustment holds the first position, and then comes bad occlusion. It is worth noting that these studies concerned bimaxillary removable complete dentures.

According to Koper, ${ }^{17}$ the fractures of the prosthetic base observed in SCRD were the result of one or all of the following causes: masticatory forces being often more intense than in a bimaxillary edentulous patient, the position of opposing natural teeth being generally unfavorable for the bilateral balance necessary for stability, and the denture flexion. Hence, reinforcement of the resin base may be envisaged. These reinforcements can be either metallic infrastructures or other materials such as carbon fibers, glass fibers, and ultra-high modulus polyethylene. ${ }^{18,19}$ It was also noted that some practitioners opt to "fill the void" left by unimaxillary edentulism, without taking into account the opposing arch which rarely presents a correct occlusal pattern. Indeed, the occlusal plane is generally disturbed by the versions, rotations, and egression.
It is one of the complexities often associated with the rehabilitation of patients with unimaxillary complete edentulism.

The occlusal plane contributes to the stabilization of the removable prosthesis in intercuspidation as well as during eccentric movements. It also contributes to the restoration of both esthetics and oral functions. ${ }^{20}$ This justifies the very significant association found between occlusal plane disturbances, on the one hand, and prosthetic instability, chewing difficulties, and speech disorders, on the other hand.

Errors in the determination of OVD were found in $27 \%$ of the patients. Bilhan et al. ${ }^{7}$ reported that practitioners prefer a relatively low OVD. According to them, this brings less discomfort. However, it is imperative to evaluate OVD correctly and to arrange a freeway space of 2-4 mm to allow efficient phonation and mastication. ${ }^{21}$

Sixty-three percent of patients were overall dissatisfied with their SCRD, conversely, in other epidemiological studies, ${ }^{22,23}$ on patients' satisfaction with their bimaxillary complete dentures of varying ages and qualities, the proportion of unsatisfied patients did not exceed $15 \%$. This confirms the complexity of the prosthetic treatment when total edentulism concerns only a single arch, due to the imbalance between the dentate and the edentulous arches.

After professional examination, the correlation between patients' satisfaction was strongly correlated with the denture qualities $\left(p<10^{-3}\right)$. This shows that the complaints expressed by the patients were mostly justified and were due to real design errors.

In spite of this generally significant relationship, the presence of some patients who are dissatisfied, despite the fact that their dentures were objectively considered acceptable, should not be neglected. The reason for their dissatisfaction could be explained by poor adaptative abilities and/or psychological reasons. Conversely, patients who are satisfied with unacceptable dentures are regarded as having better adaptative and tolerance levels. ${ }^{24}$

Another important point to consider was the correlation between the quality of the dentures and the place of its realization: SCRDs described as unacceptable were realized outside of the faculty. This revealed a lack of training of dentists in the private sector in the management of unimaxillary complete edentulism. Unlike a bimaxillary complete removable denture, which is widely taught in the university curriculum, SCRD is neglected in the courses. A revision of the training programs for dental students is, therefore, necessary.

\section{The Limitations of the Study}

- Satisfaction is a subjective notion that remains difficult to evaluate

- Several authors ${ }^{25,26}$ suggest that some factors such as age, sex, previous prosthetic experiences, or the psychological profile can influence the patients' satisfaction. This was not, unfortunately, to be performed in this study.

- The topic we dealt with was discussed especially for a bimaxillary complete denture, so we had problems in comparing our results.

\section{Conclusion}

The present results underscore the fact that SCRDs opposing a natural or restored dentition is a real prosthetic challenge for a dentist and dental technician. 
Occlusion represents the biggest problem to SCRD, for this reason, practitioners are required to give great care to the reestablishment of a correct occlusal plane, as well as the concretization of a balanced occlusal concept, to guarantee the integration and functional balance of the denture.

\section{Clinical Significance}

Based on the study results, a clinical analysis before starting prosthetic treatment was required. All the disturbances diagnosed should be corrected to design the complete denture in an ideal context.

\section{References}

1. Gillett HW. Conservatism in partial prosthetic restorations. J Dent Res 1923;5(2):Ixix-xcvii. DOI: 10.1177/00220345230050020301.

2. Sharry JJ.Complete denture prosthodontics. New York: McGraw-Hill Book Co; 1962

3. Jorgensen Ejvind B, Mojon P. The edentulous patient: epidemiology. Real Clin 1997;8(4):359-367.

4. Statistics Tunisia, National Institute of Statistics [En ligne] 2016. available: http://www.ins.tn/sites/default/files/publication/pdf/ Bulletin\%20n\%C2\%B01-2016-v3.pdf.

5. Bilhan $\mathrm{H}$, Geckili $\mathrm{O}$, et al. Evaluation of satisfaction and complications in patients with existing complete dentures. J Oral Sci 2013;55(1): 29-37. DOI: 10.2334/josnusd.55.29.

6. Sheppard IM, Schwartz LR, et al. Oral status of edentulous and complete denture-wearing patients. J Am Dent Assoc 1971;83(3): 614-620. DOI: 10.14219/jada.archive.1971.0376.

7. Bilhan $\mathrm{H}$, Erdogan $\mathrm{O}$, et al. Complication rates and patient satisfaction with removable dentures. J Adv Prosthodont 2012;4(2):109-115. DOI: 10.4047/jap.2012.4.2.109.

8. Ashraf $\mathrm{H}$. To determine the influence of complete denture prosthesis on masticatory muscle activity in elderly patients-an in vivo study. Int J Prosthet Rest Dent 2011;1(1):35-40.

9. Brunello DL, Mandikos MN. Construction faults, age, gender, and relative medical health: factors associated with complaints in complete denture patients. J Prosthet Dent 1998;79(5):545-554. DOI: 10.1016/S0022-3913(98)70176-3.
10. Smith J, Hughes D. A survey of referred patients experiencing problems with complete dentures. J Prosthet Dent 1988;60(5): 583-586. DOI: 10.1016/0022-3913(88)90218-1.

11. Goiato MC, Dos Santos DM, et al. Insertion and follow-up of complete dentures: a literature review. Gerodontology 2011;28(3):197-204. DOI: 10.1111/j.1741-2358.2010.00368.x.

12. Laurina L, Soboleva U. Construction faults associated with complete denture wearers'complaints. Stomatologija 2006;8(2):61-64.

13. Mbodj EB, Cueye $M$, et al. Do single maxillary dentures age better than bimaxillary complete dentures? Strat Proth 2015;15(3):181-185

14. Driscoll CF, Masri RM. Single maxillary complete denture. Dent Clin North Am 2004;48(3):567-583. DOI: 10.1016/j.cden.2004.03.003.

15. Naik AV. Complete denture fractures: A clinical study. J Indian Prosthodont Soc 2009;9(3):148. DOI: 10.4103/0972-4052.57084.

16. Khasawneh SF, Arab JM. A clinical study of complete denture fractures at four military hospitals in Jordan. JRMS 2003;10(2):27-31.

17. Koper A. The maxillary complete denture opposing natural teeth: Problems and some solutions. J Prosthet Dent 1987;57(6):704-707. DOI: 10.1016/0022-3913(87)90367-2.

18. Jagger $D$, Harrison $A$, et al. The reinforcement of dentures. J Oral Rehabil 1999;26(3):185-194. DOI: 10.1046/j.1365-2842.1999.00375.x.

19. Mattie PA, Phoenix RD. A precise design and fabrication method for metal base maxillary complete dentures. J Prosthet Dent 1996;76(5):496-499. DOI: 10.1016/S0022-3913(96)90007-4

20. Hüe $O$, Berteretche $M$. The occlusal plane in single - arch complete prosthodontics. Real Clin 1997;8(4):423-433.

21. Hobkirk JA. Loss of the vertical dimension of occlusion and its management implications. Int J Prosthodont 2008;22(5):520-521.

22. Čelebić $A$, Knezović-Zlatarić $D$, et al. Factors related to patient satisfaction with complete denture therapy. J Gerontol A Biol Sci Med Sci 2003;58(10):948-953. DOI: 10.1093/gerona/58.10.M948.

23. Berg E. Acceptance of full dentures. Int Dent J 1993;43(3):299-306.

24. Narain U, Garg R, et al. A Prospective Study Of The Quality Of Removable Prostheses And Patients' Satisfaction In Post-Prosthetic Phase. Internet J Dent Sci 2010;9(1):1-7.

25. Diehl RL, Foerster U, et al. Factors associated with successful denture therapy. J Prosthodontics 1996;5(2):84-90. DOI: 10.1111/j.1532849X.1996.tb00279.x.

26. Akeel RF. Effect of the quality of removable prostheses on patient satisfaction. J Contemp Dent Pract 2009;10(6):E057-E064. DOI: 10.5005/jcdp-10-6-57. 